\title{
Deaf Sign-Language Using Patients' Experiences in Health Emergencies in Wales: Perspectives for Improving Interactions
}

\author{
Anouschka Foltz ${ }^{1 *}$ and Christopher Shank ${ }^{2}$ \\ ${ }^{1}$ Institute of English Studies, University of Graz, Graz, Austria, ${ }^{2}$ School of Languages, Literatures and Linguistics, Bangor \\ University, Bangor, United Kingdom
}

Health emergency services are a critical aspect of any health care system. They need to respond quickly and efficiently, especially in life-threatening situations. In a 2019 scoping study on health and access to health care services in the Deaf community in Wales, we noted the poor perception of health emergency services by this community. In this perspective article, we present reflections and opinions on health emergency services expressed by members of the Welsh Deaf community, with a focus on texting 999 and

OPEN ACCESS

Edited by: Victoria Team

Monash University, Australia

Reviewed by:

Celia Hulme,

The University of Manchester,

United Kingdom

Jim Kyle,

Independent Researcher, Bristol, United Kingdom

*Correspondence:

Anouschka Foltz

anouschka.foltz@uni-graz.at

Specialty section

This article was submitted to Health Communication,

a section of the journal

Frontiers in Communication

Received: 20 June 2020 Accepted: 16 September 2020 Published: 23 October 2020

Citation:

Foltz A and Shank C (2020) Deaf

Sign-Language Using Patients'

Experiences in Health Emergencies in

Wales: Perspectives for Improving

Interactions.

Front. Commun. 5:572855.

doi: 10.3389/fcomm.2020.572855 the availability of British Sign Language interpreters on short notice. We also present our viewpoint to deal with the issues in both settings.

Keywords: deafness, sign language, Wales, interpreters, access to services, inequality, health emergency services

\section{INTRODUCTION}

Emergency services need to respond quickly and reliably in health emergencies; however, they often do not serve Deaf communities adequately (Reeves et al., 2002; Alexander et al., 2012; Emond et al., 2015a). Here, we focus on the Deaf community in Wales and Deafness with a capital D, which refers to "Deafness as a cultural identity" (Skelton and Valentine, 2003, p. 119), including the use of British Sign Language (BSL). This contrasts with deaf with a lower-case d, which refers to "medical descriptions of deafness" (Skelton and Valentine, 2003, p. 119).

Access to health care and experiences with the health care system differ widely for Deaf communities around the world (Nilsson et al., 2013; Kuenburg et al., 2016). Even within countries, access and experiences differ across regions (e.g., Perez et al., 2006), such that Deaf people's experiences with emergency health care in Wales may differ even from those in England or other parts of the UK. We therefore focus on previous literature that specifically considers (emergency) health care situations within the context of the Welsh Deaf community or, when needed, within a UK context.

UK Deaf community members have substantially poorer access to emergency services compared with the general population (Reeves et al., 2002; Alexander et al., 2012), and are at increased risk of preventable ill health, with chronic health conditions likely being underdiagnosed and undertreated (Emond et al., 2015b). Poor communication is one of the major reported problems (Alexander et al., 2012; Kuenburg et al., 2016). In 2002, BSL interpreters were present at only $7 \%$ of consultations with Deaf patients in hospital emergency departments (Reeves et al., 2002). Furthermore, 77\% of Deaf BSL-users reported difficulties in communicating with hospital staff (Royal National Institute for the Deaf, 2004). These problems in emergency settings are the culmination of earlier problems: About 30\% of Deaf individuals avoided seeing their family doctors because of communication difficulties 
(Royal National Institute for the Deaf, 2004). This limits Deaf patients' access to preventive services (McKee et al., 2011) and increases the possibility of emergency services being needed down the road for preventable adverse events (Bartlett et al., 2008; Schumacher et al., 2013; McKee et al., 2015). Family doctors were generally not aware of this problem, with $87 \%$ believing that they can communicate effectively with their BSL-using patients (Royal National Institute for the Deaf, 1999; Kyle et al., 2013). Many family doctors erroneously believed that lip reading, speech reading or note writing can be used to communicate health information effectively (Iezzoni et al., 2004).

Our previous scoping study (Shank and Foltz, 2019a,b,c), using group interviews with a total of 15 participants [ 11 female, four male, ages 41-90+; see (Shank and Foltz, 2019a,b,c), for more information], confirms that access to information and services in BSL remains a major issue for the Welsh Deaf community. We also noted an especially poor perception of emergency services in this community. In this perspectives paper, we therefore present a selection of Welsh Deaf community members' perspectives and opinions on texting 999 and interpreter availability in emergency situations drawn from this previous study. Our main aim is to give these Deaf community members a voice by presenting views that they have shared with us. Deaf individuals not only report fear, mistrust and frustration when dealing with health care services (Steinberg et al., 2006), they also often feel that they are voicing their needs and views, but are being ignored: "I always feel like deaf people are put last;" "I went to a meeting to talk about the ambulance service, hospitals... And everything is still the same, [...] nothing has changed. No matter what you tell them, things are still the same. It doesn't make any difference." Another aim is therefore to reiterate these needs and views in the hopes that the recommendations that we make based on them may be used to inform future policy changes.

\section{RESEARCHER CHARACTERISTICS AND THE WELSH CONTEXT}

As (hearing) researchers in the area of linguistics, we come to the topic of access to health care from a language minority, ethnographic and language rights perspective. Deaf communities are linguistic and cultural minority groups (Alexander et al., 2012). While the size of the Welsh Deaf community is not known, estimates range from 1,000 to 4,000 Deaf Welsh people (BDA, 2019; SignHealth, 2019; Action on Hearing Loss, 2020). Importantly, sign languages, such as BSL, are a fully-fledged, natural languages (Stokoe, 2005): BSL is not a signed form of English, but a distinct language with its own grammar, vocabulary and dialects (Quinn, 2017). As such, there are three languages, each with various dialects, used in Wales that are native to the region: English, Welsh, and BSL. From this perspective, Deaf individuals' needs differ from those of individuals who are deaf, hard-of-hearing or have a speech impairment in that members of the Deaf community have "language needs," not "communication needs."

This, however, is not recognized at the level of standards of care in Wales, where BSL has no legal status (BDA, 2019).
The All Wales Standards for Accessible Communication and Information for People with Sensory Loss (NHS Wales, 2013) considers a BSL interpreter to be communication support, and distinguishes this from "any other language need" (p. 7), such as services in Welsh. The language used in the above standards is also in stark contrast with the Welsh Language Standards (Welsh Government, 2018) and the Scottish Government's BSL National Plan (Scottish Government, 2017), which frame Welsh and BSL, respectively, in terms of patients' "language choice" or "preferred language" rather than in terms of a communication need. The Welsh Government (2012) further state that many people "can only communicate and participate in their care as equal partners effectively through the medium of Welsh" (p. 6) and that health care through the medium of Welsh should be "a core component of care, not an optional extra" (p. 6). No mention of similar rights for BSL-users is made in the Standards for People with Sensory Loss (NHS Wales, 2013).

\section{TEXTING 999 AND INTERPRETER AVAILABILITY}

Since 2014, Deaf individuals in the UK can text 999 on smartphones, computers and tablets through Relay UK (Relay UK, 2020a). A relay assistant reads out the caller's typed messages to the emergency operator and types the spoken responses back to the caller (Relay UK, 2020b). The problem with this service is linguistic: Deaf individuals need to text the relevant emergency information in English. Individuals who require a BSL interpreter during regular doctor's appointments should not be expected to "be precise" and provide "details" (Relay UK, 2020b) in English when texting 999 in an emergency situation.

Access to sign language is essential for Deaf people's positive health care experiences (Steinberg et al., 2006). However, the UK lacks emergency BSL interpreters, i.e., interpreters available outside of regular hours and on short notice, especially in rural areas (Perez et al., 2006; Kyle et al., 2013). This is especially the case in Wales: There are currently no interpreter training programmes (NRCPD, 2020a), and in total only 48 BSL interpreters and 4 trainee interpreters, of which around 90\% are female (NRCPD, 2020b). The Wales Interpretation and Translation Service (WITS), Action on Hearing Loss Cymru, the Center of Sign-Sight-Sound, and the Wales Council for Deaf People provide (salaried and freelance) BSL interpreters in health care settings (Auditor General for Wales, 2018). WITS alone, which is available to any public body in Wales and therefore does not only receive health-related requests, received 2,773 requests for a BSL interpreter during 2016-2017, making it the third most frequently requested language. The lack of qualified BSL interpreters in Wales makes meeting this demand difficult (Auditor General for Wales, 2018). The few BSL interpreters that currently serve Wales are typically fully booked weeks if not months into the future with non-emergency requests, such as through the Access to Work scheme (UK Government, 2020).

The number of health-related interpreter requests is also likely substantially below the actual need for BSL interpreters in Wales, as requesting an interpreter for a health appointment "seems 
almost deliberately difficult" in the UK (SignHealth, 2014, p. 13). Many Deaf patients report requesting a BSL interpreter for health care appointments, but not receiving one, especially on short notice, even if an interpreter had been promised. Thus, Deaf patients' language needs are often not met, and this is especially the case in acute hospital settings (McAleer, 2006; Middleton et al., 2010). Some emergency services and hospitals did not know how to book BSL interpreters (Earis and Reynolds, 2009; BDA, 2016), and interpreters were not always provided even for long hospital stays (SignHealth, 2014; BDA, 2016). As a result, Deaf patients admitted to hospital felt confused, vulnerable and isolated during an already stressful situation, as they couldn't communicate with staff and staff made little effort to communicate with them (SignHealth, 2014; BDA, 2016).

\section{SELECT DEAF COMMUNITY MEMBERS' VIEWS}

The Deaf community members that we talked to as part of our work exemplified the difficulty of communicating in English with 999 services in already stressful situations: "I texted the ambulance service, 999, and they were asking me all these questions, and I didn't understand what they were asking, so I had to phone my nephew at one o'clock in the morning to phone 999 for me;" "When you text control [999], there are all these questions that they are asking you. [...] And all that we want to be able to say is 'We need an ambulance. My partner is having a heart attack.' [...] We're panicking, we don't understand the English, there are all these questions being texted to us. It's hard enough for us to understand it anyway without panicking at the same time." One Deaf individual reported that 999 operators refused to believe that they did not understand English: "I already said to them 'I don't understand your words'. And they kept texting the same questions again. And I kept saying to them 'I don't understand you. I'm Deaf.' [...] They just refused to accept that I couldn't understand them." Another Deaf individual sums up this misconception: "They all think that Deaf people can read, but they don't realize, for a lot of us, we don't understand English."

Due to such language problems, several Deaf individuals reported that "you can just dial 999 and leave it, and they will recognize my mobile." This strategy puts Deaf individuals at risk: Silent mobile phone 999 calls are transferred to the automated Silent Solutions system, used throughout the UK with the main purpose of filtering out the $\sim 20,000$ daily accidental or hoax 999 calls (IOPC, 2019). The system prompts callers to cough, tap the handset, and finally to press 55 to indicate that they need help. Not pressing 55 terminates the call and the caller's location is not tracked (IOPC, 2020). Silent landline 999 calls do allow for location tracking, but help will only arrive if the operator is concerned for the caller's safety (IOPC, 2020). Many Deaf individuals use smartphones. When calling 999, they would not hear the Silent Solutions prompts, and their call would likely be terminated.

Interpreter availability was the most common issue for the Deaf community members we talked to. Even in non-emergency situations, interpreters are essential: "I always say 'Make sure that you've booked an interpreter. Don't let me down. [...] I don't want to be going through this again;" "it can be difficult when there is no interpreter. It makes you totally anxious." While interpreters in Wales are in theory available 24/7 (Auditor General for Wales, 2018), many Deaf individuals reported problems with interpreter provision on short notice in hospital settings: "My husband went up to hospital and nobody came at all. And it was offered as 24-7 support. [...] I had nobody to help." One participant concluded, "I have had so many bad experiences in the hospitals, so has my husband."

This situation has caused mistrust with services providing interpreters: "They have let us down so many times. They've said 'Yeah, yeah, we'll get you an interpreter', and they don't. [...] And that's made me feel worse, made me feel down. [...] And this is happening all the time." Deaf community members also noted issues with interpreter availability, saying "most are never available." But mistrust was mostly directed at hospitals: "They tell us they will try to find one, but when I ask an interpreter directly, they say they never contacted me;" "The hospital will swear blind that they have tried to find an interpreter [...] I will then contact an interpreter, and they will say, 'No, they never contacted me;" "They all say that. We tried, but couldn't find anyone."

\section{FUTURE DIRECTIONS AND RECOMMENDATIONS}

Based on our knowledge and experience as researchers and linguists, the Welsh context, and our face-to-face interactions with members of the Deaf community, we offer recommendations for how to improve services for Deaf individuals in health emergency situations.

Implementing our recommendations requires a substantial expansion of services and training. We are aware that what we propose has financial implications, but we believe that concerns about potential costs should come after a fair and open assessment of the Deaf community's needs (and legal rights and protections afforded by the law). Furthermore, the current health inequalities that Deaf people in the UK face cost

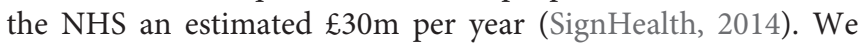
therefore believe that it would be advantageous to reframe the discussion around the potential savings that could be achieved by implementing our recommendations.

In terms of 999 services, we propose that a 24/7, pan-Wales BSL emergency video service, available without prior registration and without the need to first download an app, is needed to avoid putting Deaf community members at greater risk in emergency situations. A service that requires English is not a reasonable adjustment under the Equality Act (UK Government, 2010). Technology to offer BSL emergency services already exists, and is already used for non-emergency police services (SignVideo, 2020) or GP appointments (Whereby, 2020). Video relay and remote interpreting services are already available in BSL on smartphones, computers, and tablets (e.g., InterpreterNow, 2020; SignVideo, 2020 etc.), can connect Deaf individuals with an interpreter in under $30 \mathrm{~s}$ (SignVideo, 2020), and are available 24/7 (InterpreterNow, 2020). However, there are various different 
services that differ slightly in what they offer, may require registration or the installation of an app (e.g., InterpreterNow, 2020), and may or may not be permanent (e.g., BSL Health Access, 2020). What is needed in an emergency is a unified 24/7 service that can be contacted from anywhere in Wales without the need for an app or prior registration. Such a service, however, should not replace Relay UK's already existing 999 emergency services, but be offered in addition.

Furthermore, we argue that interpreter availability in Wales must be improved. More BSL interpreters need to be trained and paid sufficiently to meet demand (Auditor General for Wales, 2018) and training programmes should be available in Wales. Hospital and emergency staff should know how to book interpreters (Earis and Reynolds, 2009; BDA, 2016). To ensure 24/7 availability, there should be an on-call system for BSL interpreters, similar to doctors. Both on-site and video interpreting should be available (Earis and Reynolds, 2009), with an interpreter available via video call until an on-site interpreter arrives in emergency situations. Currently, the responsibility to request an interpreter is on the patient (Auditor General for Wales, 2018). Instead, Deaf patients' records should state their language needs and preferences, and interpreters should be booked automatically for all appointments, follow-ups, referrals and emergencies, without patients needing to make a request (SignHealth, 2014; BDA, 2016). Patients should be informed that an interpreter has been secured and who the interpreter is. If possible, patients should have a choice of interpreter, e.g., someone of the same gender or who knows the patient's history (BDA, 2016; Auditor General for Wales, 2018). Health professionals should also be aware of the role of interpreters (Auditor General for Wales, 2018), who are there for them as much as for the patient: "Without the interpreter they would not be able to take a make a proper clinical assessment, explain the diagnosis and treatment, or discuss the patient's concerns" (SignHealth, 2014, p. 13). Health professionals should adapt to Deaf patients' language needs, not the other way around (Kyle et al., 2013; NHS Wales, 2013). Overall, "health services should be responsible for the provision of, and payment for, registered sign language interpreters so they can communicate safely with Deaf people in primary and secondary healthcare settings" (SignHealth, 2013, p. 9). Finally, long term goals should also include training more Deaf and BSL-proficient medical staff, especially in hospital settings (Middleton et al., 2010).

\section{DISCUSSION}

In this perspectives article, we focused on two examples of how emergency services still do not adequately serve the Welsh Deaf community. We have drawn on the previous literature and Deaf community members' voices to inform our opinions and recommendations as to how emergency services can be improved. In summary, we recommend a pan-Wales 999 BSL video emergency service provided in addition to Relay UK (2020a), and for on-site or online BSL interpreters to be secured automatically and, if needed, on short notice. Most importantly, any such services need to be developed by or with
Deaf community members and be made available in addition to existing provisions. Whenever possible, Deaf patients should have a choice of which service they prefer.

Deaf patients repeatedly encounter barriers in accessing health care. The resulting "barrier fatigue" causes low expectations and anxiety at the prospect of engaging with these services. Some Deaf people "would rather risk being ill than face yet more poor communication" (SignHealth, 2014, p. 11). We need to be clear: These barriers would not exist if all health care services were provided to Deaf patients in BSL through native-signing staff. This level of training may not be feasible, but we need to be aware that it is the health care system that creates the barriers, not the Deaf patients. It is therefore up to the health care services and professionals to begin breaking the cycle and create more positive experiences.

\section{DATA AVAILABILITY STATEMENT}

The datasets presented in this article are not readily available because they consist of video recordings and contain personal stories from members of a very small community. The data can therefore not be anonymized and are not publicly available to protect participants' anonymity. Requests to access the datasets should be directed to Anouschka Foltz, anouschka.foltz@unigraz.at.

\section{ETHICS STATEMENT}

The studies involving human participants were reviewed and approved by College of Arts, Humanities and Business' Research Ethics Committee, Bangor University, Reference Number: CAHB08. The patients/participants provided their written informed consent to participate in this study.

\section{AUTHOR CONTRIBUTIONS}

AF and CS engaged with the Deaf community and health professionals. AF wrote the first draft of the paper. CS provided feedback and contributed to later drafts of the paper. All authors contributed to the article and approved the submitted version.

\section{FUNDING}

This work was funded through the Public Health Wales Grant Scoping Study: Health and Deafness in Wales Survey awarded to CS and AF. The open access publication fees are covered by the University of Graz.

\section{ACKNOWLEDGMENTS}

We would like to thank the members of the Welsh Deaf community who shared their views with us. We would also like to thank Sarah Thomas, the staff, the interpreters at the Center of Sign-Sight-Sound in Colwyn Bay and Louise McGrath, the staff, and the interpreters at the Wales Council for Deaf People in Pontypridd for their invaluable assistance in running the group 
interviews from which the views in this perspectives paper are drawn. Furthermore, we would like to acknowledge the financial support of Public Health Wales and the University of Graz. Particular thanks go to Helen Foulkes as well as one Welsh BSL interpreter and four members of the Welsh Deaf community who wished to remain anonymous for their valuable feedback on the

\section{REFERENCES}

Action on Hearing Loss (2020). Facts and Figures. Available online at: https:// actiononhearingloss.org.uk/about-us/research-and-policy/facts-and-figures/ (accessed 26 August, 2020).

Alexander, A., Ladd, P., and Powell, S. (2012). Deafness might damage your health. Lancet 379, 979-981. doi: 10.1016/S0140-6736(11)61670-X

Auditor General for Wales (2018). Speak My Language: Overcoming Language and Communication Barriers in Public Services. Cardiff: Wales Audit Office.

Bartlett, G., Blais, R., Tamblyn, R., Clermont, R. J., and MacGibbon, B. (2008). Impact of patient communication problems on the risk of preventable adverse events in acute care settings. Can. Med. Assoc. J. 178, 1555-1562. doi: $10.1503 / \mathrm{cmaj} .070690$

BDA (2016). Access \& Inclusion (Health) Review: Impact and Influence on Health Care Services Between Deaf British Sign Language Users and Service Providers in Scotland. Glasgow: British Deaf Association Scotland.

BDA (2019). Legal Status of BSL. Available online at: https://bda.org.uk/project/ sign-language-regional-legal-status/ (accessed 28 August, 2019).

BSL Health Access (2020). FAQS. Available online at: https://bslhealthaccess.co.uk/ faqs/ (accessed 26 August, 2020).

Earis, H., and Reynolds, S. (2009). Deaf and Hard-of-Hearing People's Access to Primary Health Care Services in North East Essex: A report for North East Essex Primary Care Trust. Colchester: HNS North East Essex.

Emond, A., Ridd, M., Sutherland, H., Allsop, L., Alexander, A., and Kyle, J. (2015a). Access to primary care affects the health of Deaf people. Br. J. Gen. Practice 65, 95-96. doi: 10.3399/bjgp15X683629

Emond, A., Ridd, M., Sutherland, H., Allsop, L., Alexander, A., and Kyle, J. (2015b). The current health of the signing Deaf community in the UK compared with the general population: a cross-sectional study. BMJ Open 5:e006668. doi: 10.1136/bmjopen-2014-006668

Iezzoni, L. I., O’Day, B. L., Killeen, M., and Harker, H. (2004). Communicating about health care: observations from persons who are deaf or hard of hearing. Ann. Int. Med. 140, 356-362. doi: 10.7326/0003-4819-140-5-200403020-00011

InterpreterNow (2020). Welcome to the NHS 111 BSL Service. Available online at: https://interpreternow.co.uk/nhs111 (accessed 19 March, 2020).

IOPC (2019). National Campaign to Raise Awareness of the Silent Solution System. Available online at: https://www.policeconduct.gov.uk/news/nationalcampaign-raise-awareness-silent-solution-system (accessed March 18, 2020).

IOPC (2020). What to Do if you Need Urgent Police Help Through the 999 Service, but Can't Speak. Available online at: https://www.policeconduct.gov. uk/sites/default/files/Documents/research-learning/Silent_solution_guide.pdf (accessed March 18, 2020).

Kuenburg, A., Fellinger, P., and Fellinger, J. (2016). Health care access among deaf people. J. Deaf Stud. Deaf Edu. 21, 1-10. doi: 10.1093/deafed/env042

Kyle, J., Sutherland, H., Allsop, L., Ridd, M., and Emond, A. (2013). Deaf Health; Analysis of the Current Health and Access to Health Care of Deaf People in the UK. Part 1: Health Assessment and Quantitative Data. Bristol: Centre for Deaf Studies and School of Social and Community Medicine at the University of Bristol and the Deaf Studies Trust, Bristol.

McAleer, M. (2006). Communicating effectively with deaf patients. Nursing Standard 20, 51-54. doi: 10.7748/ns.20.19.51.s57

McKee, M. M., Barnett, S. L., Block, R. C., and Pearson, T. A. (2011). Impact of communication on preventive services among deaf American Sign Language users. Am. J. Prev. Med. 41, 75-79. doi: 10.1016/j.amepre.2011. 03.004

McKee, M. M., Winters, P. C., Sen, A., Zazove, P., and Fiscella, K. (2015). Emergency department utilization among deaf American Sign Language users. Disabil. Health J. 8, 573-578. doi: 10.1016/j.dhjo.2015.05.004 recommendations that we make in this article. We realize that there are many more recommendations to be made that haven't made it into this paper. It should also be noted that the views presented in this article are our own, and should not be taken to reflect the views of any of the parties who contributed to the project.

Middleton, A., Turner, G. H., Bitner-Glindzicz, M., Lewis, P., Richards, M., Clarke, A., and Stephens, D. (2010). Preferences for communication in clinic from deaf people: a cross-sectional study. J. Eval. Clin. Pract. 16, 811-817. doi: 10.1111/j.1365-2753.2009.01207.x,

NHS Wales (2013). All Wales Standards for Accessible Communication and Information for People with Sensory Loss. Available online at: http://www. cardiffandvaleuhb.wales.nhs.uk/sitesplus/documents/1143/Sensory\%20Loss \%20Standards.pdf (accessed August 26, 2020).

Nilsson, A. L., Turner, G. H., Sheikh, H., and Dean, R. (2013). A Prescription for Change: Report on EU Healthcare Provision for Deaf Sign Language Users. Available online at: https:/www.diva-portal.org/smash/get/diva2:586691/ FULLTEXT02.pdf (accessed August 26, 2020).

NRCPD (2020a). Approved Courses. Available online at: https://www.nrcpd.org.uk/ approved-courses (accessed June 10, 2020).

NRCPD (2020b). NRCPD: The National Registers of Communication Professionals working with Deaf and Deafblind People. Available online at: https://www. nrcpd.org.uk/ (accessed June 10, 2020).

Perez, I. A., Wilson, C. W., King, C., and Pagnier, C. (2006). Translating, Interpreting and Communication Support: A Review of Provision in Public Services in Scotland. Edinburgh: Scottish Executive Social Research.

Quinn, G. (2017). British Sign Language (BSL). In: The Routledge Handbook of Pragmatics, eds A. Barron, Y. Gu, and G. Steen (London: Routledge), 55-60. doi: 10.4324/9781315668925-6

Reeves, D., Kokoruwe, B., Dobbins, J., and Newton, V. (2002). Access to Primary Care and Accident \& Emergency Services for Deaf People in the North West. A report for the NHS Executive North West Research and Development Directorate.

Relay UK (2020a). About Relay UK. Available online at: https://www.relayuk.bt. com/about-relay- uk.html (accessed 18 March, 2020).

Relay UK (2020b). Contact 999 Using Relay UK. Available online at: https:// www.relayuk.bt.com/how-to-use-relay-uk/contact-999-using-relay-uk.html (accessed March 18, 2020).

Royal National Institute for the Deaf (1999). Can You Hear Us? Deaf People's Experience of Social Exclusion, Isolation and Prejudice. London: Royal National Institute for the Deaf.

Royal National Institute for the Deaf (2004). A Simple Cure: A National Report Into Deaf and Hard of Hearing People's Experiences of the National Health Service. London: Royal National Institute for the Deaf.

Schumacher, J. R., Hall, A. G., Davis, T. C., Arnold, C. L., Bennett, R. D., Wolf, M. S., and Carden, D. L. (2013). Potentially preventable use of emergency services: the role of low health literacy. Medical Care 51, 654-658. doi: 10.1097/MLR.0b013e3182992c5a

Scottish Government (2017). British Sign Language (BSL): National Plan 2017 to 2023. Available online at: https://www.gov.scot/publications/british-signlanguage-bsl-national-plan-2017-2023/ (accessed 26 August, 2020).

Shank, C., and Foltz, A. (2019a). Health and Wellbeing for Deaf Communities in Wales: Scoping for a Wales-wide survey. Available online at: http:// deaf-communities-wales.bangor.ac.uk/Health\%20and\%20Wellbeing\%20for \%20Deaf\%20Communities\%20in\%20Wales\%20Report.pdf (accessed August 26, 2020).

Shank, C., and Foltz, A. (2019b). Health and Wellbeing for Deaf Communities in Wales Report. [British Sign Language version]. Available online at: http:// deaf-communities-wales.bangor.ac.uk/bsl-report.php.en (accessed August 26, 2020).

Shank, C., and Foltz, A. (2019c). Iechyd a Llesiant ar gyfer Cymunedau Byddar yng Nghymru: Cwmpasu ar gyfer Arolwg Cymru gyfan. Available online at: http://deaf-communities-wales.bangor.ac.uk/Health\%20and\%20Wellbeing \%20for\%20Deaf\%20Communities\%20in\%20Wales\%20Report\%20-\%20CY. pdf (accessed August 26, 2020). 
SignHealth (2013). Research Into the Health of Deaf People. Research Study Conducted by Ipsos MORI for Sign Health. Revised by Pauline Heslop and Sophie Turnbull. London: Sign Health.

SignHealth (2014). Sick of It: A Report Into the Health of Deaf People in the UK. London: SignHealth; Bristol: University of Bristol.

SignHealth (2019). Deaf Awareness. Available online at: https://www.signhealth. org.uk/about-deafness/deaf-awareness/ (accessed 27 August, 2019).

SignVideo (2020). Our Story. Available online at: https://www.signvideo.co.uk/ our-story/ (accessed March 19, 2020).

Skelton, T., and Valentine, G. (2003). Political participation, political action and political identities: young D/deaf people's perspectives. Space Polity 7, 117-134. doi: 10.1080/1356257032000133892

Steinberg, A. G., Barnett, S., Meador, H. E., Wiggins, E. A., and Zazove, P. (2006). Health care system accessibility. J. Gen. Int. Med. 21, 260-266. doi: 10.1111/j.1525-1497.2006.00340.x

Stokoe Jr, W. C. (2005). Sign language structure: an outline of the visual communication systems of the American deaf. J. Deaf Stud. Deaf Edu. 10, 3-37. doi: 10.1093/deafed/eni001

UK Government (2010). Equality Act 2010. Available online at: https://www. legislation.gov.uk/ukpga/2010/15/contents (accessed 22 October, 2018).

UK Government (2020). Guidance. Access to Work: Factsheet for Customers. Available online at: https://www.gov.uk/government/publications/access-towork-factsheet/access-to-work-factsheet-for-customers (accessed 26 August, 2020).
Welsh Government (2012). More than just words... Strategic Framework for Welsh Language Services in Health, Social Services and Social Care. Available online at: http://www.wales.nhs.uk/ sites3/documents/415/web\%20-\%2016184_narrative_e_web.pdf (accessed 26 August, 2020).

Welsh Government (2018). Consultation - Summary of Response: Welsh Language Standards (Health Sector) Regulations. Available online at: https://gov.wales/ sites/default/files/consultations/2018-02/180227-welsh-language-standardshealth-sector-regulations-summary\%20of\%20response.pdf (accessed 26 August, 2020).

Whereby (2020). Freedom to Work From Anywhere. Available online at: https:// whereby.com/ (accessed 6 June, 2020).

Conflict of Interest: The authors declare that the research was conducted in the absence of any commercial or financial relationships that could be construed as a potential conflict of interest.

Copyright (c) 2020 Foltz and Shank. This is an open-access article distributed under the terms of the Creative Commons Attribution License (CC BY). The use, distribution or reproduction in other forums is permitted, provided the original author(s) and the copyright owner(s) are credited and that the original publication in this journal is cited, in accordance with accepted academic practice. No use, distribution or reproduction is permitted which does not comply with these terms. 